Original article

\title{
THE IMPACT OF OVERHEADS VARIATION ON TIME-COST OPTIMISATION OF BUILDING INFRASTRUCTURE PROJECTS
}

\author{
Dimitrios D. Kantianis
}

\begin{abstract}
Panteion University of Social and Political Sciences, Department of Economic and Regional Development, Athens, Greece
\end{abstract}

Received:23 November 2020 Revised: 16 December 2020 Accepted: 28 December 2020

\begin{abstract}
The research aims at investigating the impact of indirect expenses (overheads) variation on time-cost optimisation (TCO) of building infrastructure projects. The study's main objectives are to propose a practical methodology for time-cost planning of buildings and to analyse the relationship between level of overheads and minimum project duration with respect to contractor's profitability. The methodology entails the development of a TCO linear programming (LP) model founded on PERT/CPM network analysis, and its subsequent implementation to an actual public building project - a three-storey nursery school for a municipality - for the assessment of minimum project duration for a given gross profit when altering the fixed amount of overheads. The LP mathematical model is solved with Solver optimisation add-in for Microsoft Excel ${ }^{\odot}$. Useful prototype minimum project duration vs. project overheads trade-off curves are derived to support project management decisions. The proposed TCO approach may serve as a valuable scheduling tool, providing stakeholders important insight into the relationship between level of project overheads, profit and duration. The study is expected to assist both construction researchers and practitioners towards more effective decisionmaking in the planning process of building projects.
\end{abstract}

Keywords: Construction, optimisation, overheads, scheduling.

\section{INTRODUCTION}

Construction planning decision-making is mainly focused on the establishment of the optimal trade-off between duration and cost of a project prior to its site execution. This time-cost relationship is a function of the technological order of the various activities of a project, the resources required and the associated costs. The optimisation of this relationship can be a quite complex and challenging task (Cusack, 1985). Previous experience is mainly used to estimate project duration and cost. Typically, the construction project is broken down into work activities to which several resources can be assigned so that durations and costs estimated. The activities are linked together according to their precedence relationships to form a project network. Scheduling techniques are then used to analyse the network to identify critical path(s) and project duration and cost (Burns et al., 1996). Difficulties arise because, for the hundreds of activities in a project, there are various options of completing these activities using different crew sizes or equipment. This creates the classic combinatorial search problem for construction engineers to identify the best selections of resources that produce the minimum total cost possible to complete the project. Because of the time-cost relationship

Corresponding author. Email: dkant@ panteion.gr

ISSN 2560-4961 (online)

Copyright (C) 2020, The Authors. Published by IPMA Serbia.

This is an open access article under the CC BY-NC 4.0 license (https://creativecommons.org/licenses/by$\mathrm{nc} / 4.0 /$ )

Doi: $10.18485 /$ epmj.2020.10.2.3 
among activities, it usually takes several iterations to select the proper methods, equipment, crew sizes and working hours to obtain an acceptable overall project duration within the contractual time limit (Feng et al., 2000).

In public works, penalties are commonly imposed on contractors that exceed contract project duration; failure to meet the contractual time requirement will put contractors in breach of contract and thus liable for any damages suffered by the owner due to late project completion. Furthermore, on a job in progress, the owner may desire an earlier completion date than originally called for by the contract and may request that the contractor quote a price for expediting the work. On the other hand, the contractor may wish to complete the project by a certain date to avoid adverse weather, to free human resources and equipment for other work and/or to receive an early completion bonus from the client (Sears et al., 2015). The construction planner then normally aims at three possible schedule objectives: minimizing the project makespan subject to a fixed upper bound of money (the budget restriction); minimizing the total cost of the project subject to a given bound on the project duration (the deadline restriction) (Brucker et al., 1999); or combining the two objectives by generating an efficient time-cost profile over a set of feasible durations (the complete horizon objective) (Vanhoucke, 2013).

Reducing project time is accomplished by compressing the duration of some of its constituent critical activities by increasing the direct costs of resources required. However, by saving project time, there will also be savings in the indirect general expenses (overheads). Thus, balancing increasing direct costs and decreasing indirect costs is the subject of time-cost optimisation (TCO) analysis. Increasing the resources allocated for the activity reduces the duration of the activity, but a point is reached where the use of additional resources does not result in any overall savings on the project (Baldwin, \& Bordoli, 2014). This point representing the optimum total project cost is shown in Figure 1.

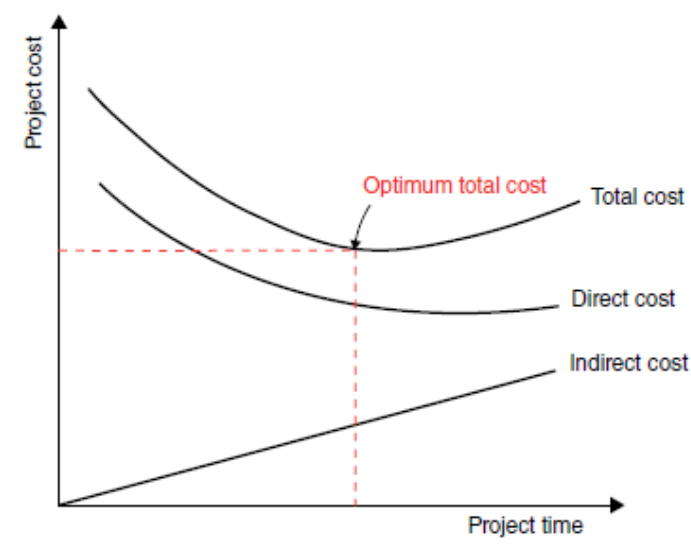

Figure 1: Optimum TCO point in time-cost relationship (Source: Baldwin, \& Bordoli,

2014)

TCO has been studied extensively since the development of the critical path method (CPM) (Vanhoucke, \& Debels, 2007). According to Sonmez and Bettemir (2012), these studies can be classified in the following three categories: mathematical models, seeking for exact solutions; heuristic procedures, resulting in near-optimal solutions; and meta-heuristic algorithms, in search for optimal or nearoptimal results. Mathematical methods can convert problems of TCO to mathematical modelling through linear programming (LP), integer programming (IP), or dynamic programming (DP) to exactly solve the problem (e.g., Burns et al., 1996; Chassiakos, \& Sakellaropoulos, 2005; De et al., 1995; Moussourakis, \& Haksever, 2004). In the early 1960s, Kelley (1961) and Fulkerson (1961) formulated models using LP and network flow computations by assuming bounded, piecewise linear, continuous, convex, non-increasing time-cost relationships. Meyer and Shaffer (1963) used IP to handle more complex timecost functions. The practicality of the aforementioned approaches was questioned by Cusack (1985) due to the large number of variables and constraints needed and the necessity for time consuming mathematical analysis to transform project data into standard IP form. Cusack (1985) suggested an IP model based on convex time-cost curves joined by points of breakthrough, thus reducing the number of variables and constraints so that the analysis could be automated using a microprocessor. However, the proposed model was limited to a maximum number of hundred work activities. Robinson (1975) developed a 
DP approach to solve TCO problems which require special network relationships. Reda and Carr (1989) used mixed IP to solve a TCO problem within related activities. Maghrebi et al. (2013) proposed a novel mathematical deterministic model based on path constraints, rather than activities. The simplicity of the model and the shorter time required for the solution are its main strengths. Generally, the advantages of mathematical models include efficiency and accuracy. However, constraints and objective function formulation can be time-consuming and error prone. Besides, mathematical programming knowledge is necessary for correct formulation of the model and few construction planners are trained to perform this type of formulation, especially for large networks (Williams, 2003). Concise reviews of mathematical programming attempts can be found in Brucker et al. (1999); Ahuja and Thiruvengadam (2004); and Moselhi and Roofigari-Esfahan (2013). Heuristics require less computational effort than mathematical methods. Early examples of heuristic approaches can be found in the work of Fondahl (1961); Prager (1963); Siemens (1971); and Goyal (1975). Moselhi (1993) developed an algorithm based on schedule compression. Generally, heuristic methods provide a fast way to obtain near-optimal solutions with a reasonable amount of computational effort but do not guarantee optimality. In addition, solutions offered by heuristic methods do not provide the range of possible solutions, making it difficult to experiment with different scenarios for what-if analysis (Burns et al., 1996). Subsequently, several meta-heuristic approaches searching for optimal or near-optimal solutions have been developed: genetic algorithms (GA) (ElRayes, \& Kandil, 2005; Eshtehardian et al., 2009; Feng et al., 1997; Hegazy, 1999; Li, \& Love, 1997; Sonmez, \& Bettemir, 2012), neural networks (NN) (Adeli, \& Karim, 1997), particle swarm optimisation (PSO) (Elbeltagi et al., 2005; Yang et al., 2007), and ant colony optimisation (ACO) (Kalhor et al., 2011; Ng, $\&$ Zhang, 2008). A recent state of art review on meta-heuristic TCO approaches is provided by Albayrak and Özdemir (2017). Yang (2005) stated that the time-cost relationship of each activity can be piecewise linear (Cusack, 1985; Fondahl, 1961; Kelley, 1961), convex (Foldes, \& Sourmis, 1993), concave (Falk, \& Horowitz,
1972), quadratic (Deckro et al., 1995), and discrete (De et al., 1995; Liu et al., 1995; Skutella, 1998). The proposed in this paper mathematical project time-cost optimisation model approximates both direct and indirect costs as linear functions of time, like in the original CPM (Kelley, \& Walker, 1959; Lockyer, 1974). This linear relationship between direct cost and duration can be seen in Figure 2.

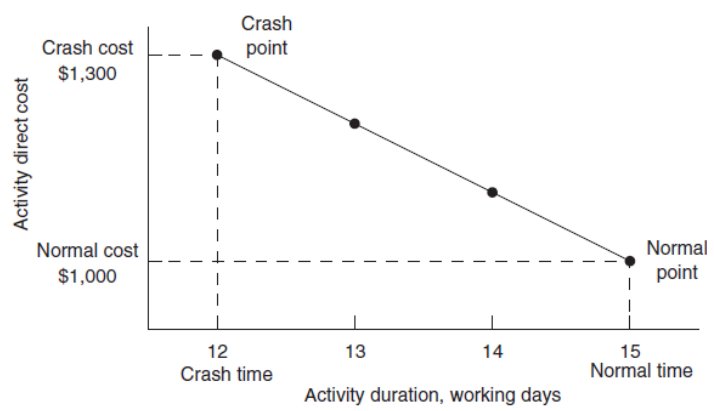

Figure 2: Linear relationship between activity direct cost and duration (Source: Sears et al., 2015)

The effective management of overhead costs has been suggested as the main tool to improve a construction enterprise's financial situation (Enshassi et al., 2008). Nonetheless, contractors often overlook the importance of indirect expenses estimation due to its low percentage contribution to the contract sum (Chan, \& Pasquire, 2002). Moreover, planning the optimal project completion is a major construction management aspect for building constructors towards maximising their profit margins and succeeding client's satisfaction through the expedient delivery of the final product for building owners to start reaping the anticipated benefits (Elazouni et al., 2015). Notwithstanding the significance of both indirect expenses' management and TCO on project success, to the author's knowledge, there is no research exploring the effect of indirect costs' variation on TCO and the resulting project profitability. A few studies have concentrated on assessing the effect of budget (funding) uncertainty on TCO (e.g., El-Kholy, 2013; Yang, 2005). In addition, the foregone literature review on the currently available crashing solutions suggests that a practical knowledge gap remains in the adoption of a widely accepted by the construction sector whilst simple and easy-to-use TCO 
methodology for the effective time-cost planning of construction projects.

The paper, thus, aims at assessing the impact of indirect disbursements (overheads) variation in project crashing of building infrastructure projects. The main objectives of the study are: i) to propose a simple and practical methodology for solving the TCO problem in construction projects; and ii). to analyse the relationship between the level of project indirect costs and minimum (crash) project duration for fixed percentages of contractor's profit. The research methodology consists of: i). developing a TCO LP spreadsheet model founded on the PERT/CPM activity-on-node (AoN) network analysis; ii). implementing the above LP model to a real public building infrastructure project a three-storey nursery school for a municipality - in order to calculate minimum project duration when changing the amount of indirect expenses (sensitivity analysis); and iii). using the results from the analyses to assist project stakeholders towards more effective decision-making in infrastructure project planning.

\section{DISBURSEMENTS IN INFRASTRUCTURE PROJECTS}

In construction projects, the two main cost categories are direct and indirect expenses. Direct cost is defined as the cost of labour used, embedded materials and installed equipment, directly involved in the physical construction of the building infrastructure (CIOB, 2015). Therefore, direct expenses for public works contractors typically include: labour, particularly hourly workers, for whom a labour expense can be directly linked to a particular work item; materials, such as concrete, rebar, bricks, lumber, paint, drywall, carpet and structural steel; installations, such as elevators, air-conditioning units and sanitary fixtures; heavy equipment, mainly construction site machinery (bulldozers, excavators, cranes and concrete pumps); subcontractors, even though subcontractors' charges comprise labour, materials, equipment, overheads, and possibly sub-subcontractors, general contractors treat these charges as a direct cost; and other miscellaneous costs, such as fees for issuing town planning permits or expenses for lawyers and special consultants hired for specific tasks in projects (Mubarak, 2015). Indirect cost (or overhead expenses) is defined as all costs which do not become a final part of the building infrastructure, but which are necessary for the completion of the facility; these costs may include (but are not limited to) field administration, direct supervision, capital tools, start-up costs, contractor's fees, insurance, taxes, etc. (Westney, 1997). Hence, contractors' indirect costs include: project (site field) overheads (or job overheads), such as project staff (project manager, project superintendent, project engineer, receptionist or secretary, clerk), office containers and other temporary structures, cars and trucks assigned to the project team, office light equipment (copying machine, fax machine, computers), temporary utilities (electricity, water, drinking water/ice, telephones, cell phones, gas, portable toilets); other indirect project-related expenses, such as power generators and projectors used to provide light during night working hours; general (headoffice) overheads, such as main office expenses (rent, lease, maintenance, utilities), head office personnel, equipment, vehicles and services, such as lawyers and accountants (not working exclusively for a specific project), other main office expenses, such as advertising and charity contributions; profit which is estimated as a percentage by the contractor before taking on the project, it usually ranges between $5 \%$ and $10 \%$ (although it may occur outside this range) and depends on many project-specific factors, prevailing economic conditions and contractors' financial status (the term "profit" is essentially the contractor's "return for taking risk", i.e. the amount that is usually charged in proportion to the risk taken in undertaking a project); contingency fees, an additional sum of money or percentage allocated for unknown events most likely to occur during construction (directly proportional to the above risk) (Mubarak, 2015).

The conventional method of construction project cost estimation is still based on determining the direct (variable) costs (for materials, labour, plant, and subcontractors) and then adding on top a cost-plus percentage to arrive at the proposed price. This added gross margin is expected to cover total indirect (fixed) expenses (overheads) plus contingency and what remains is gross profit (BCIS, 2012). A difficulty can arise regarding the means by 
which overheads are allocated and absorbed. Since estimators often misallocate overhead project costs, a project might look like promising a large gross margin, when in fact it does not, and another project might look like having a small gross margin, when in fact it has a larger one (Raz, \& Elnathan, 1999). Therefore, construction firms are constantly faced with the dilemma of having to adjust the level of their overheads. In recession periods when predetermined volume targets are not reached, whether due to low business activity or because of unsuccessful bidding, builders may face severe financial difficulties, even insolvency, unless they reduce their overheads usually by means of redundancies, disposal of facilities or assets, discontinuation of services, and nonmaintenance of records and databases. However, these measures may cause a negative effect on a company's ability to compete and, when a market recovery occurs, contractors with reduced overheads may find themselves at a disadvantage from both capacity and competitive points of view (Eksteen, \& Rosenberg, 2002). Therefore, accurate estimation of project overheads not only assists in improving the chance of success in bidding, but also serves as a profit centre for the contractor (Chan, \& Pasquire, 2002).

In this research, after setting the required fixed percentage of contractor's profit, the proposed TCO mathematical model is used to examine the relationship between indirect (overhead) project cost and minimum (crash) project duration.

\section{TIME-COST OPTIMISATION MODEL DEVELOPMENT}

Today's project scheduling practice uses solely AoN networks; the technique is more flexible due to its enhanced capabilities in modelling projects closer to reality (Hajdu, 2013). In an AoN network, work activities are assigned to nodes instead of arcs. A project is defined as an acyclic and directed graph $G=(N, R)$ with a set of interacting activities with required time and resources for their completion. The project's structural analysis provides a decomposition of activities into a set of nodes $\mathrm{N}$ and a set of technological precedence relationships $\mathrm{R}$ between them. Set $\mathrm{N}$ consists of $n$ work activities $i=\{1, \ldots, n\}$ to be scheduled plus two auxiliary (dummy) activities, 0 and $n+1$, representing project start and finish, respectively. The precedence relationships are represented as pairs of activities $(a, b)$ where $a$ $\neq b$, denoting that beginning time of activity $a$ affects earliest start time of activity $b$. A duration $d_{a}$ is assigned to each project activity $a$ and a time lag $\delta_{a b}$ to each pair $(a, b) \in \mathrm{R}$. The temporal constraint then is $\delta_{a b} \leq s_{b}-s_{a}$, with $s_{a}$ and $s_{b}$ the start times of activities $a$ and $b$, respectively. If $(a, b) \in \mathrm{R}$, activity $b$ cannot start earlier than $\delta_{a b}$ time units (normally working weeks or days) after the start of activity $a$. If $\delta_{a b}$ $=d_{a}$, the above inequality constraint is referred to as precedence constraint between activities $a$ and $b$. The AoN network analysis then consists of (Oxley, \& Poskitt, 1996): (1) calculating the earliest finish (EF) times of the activities by a forward pass through the network and selecting the longest path (i.e. the final earliest completion time gives the project duration); (2) calculating the latest finish (LF) times of the activities by a backward pass through the network and selecting the longest path (the final latest finish time is the same as its earliest completion time and gives the same project duration); (3) calculating the total float (TF) of the activities which is either latest start times minus earliest start times (LS - ES) or latest finish times minus earliest finish times (LF EF) (both give the same result); and (4) identifying the critical activities, i.e. the ones with zero total float, to determine the critical path of the project. The complete project network definition is as follows:

$\mathrm{G}$ an acyclic and directed graph, where $\mathrm{G}=$ $(\mathrm{N}, \mathrm{R})$

$\mathrm{N}$ set of nodes in project network, each node representing a work activity

$\mathrm{R}$ set of arcs in the project network, representing the immediate precedence relationships between activities, with each activity pair $(a, b) \in \mathrm{R}$ with $a \neq b$, denoting that starting time of activity $a$ affects earliest start time of activity $b$

$i \quad$ activity to be scheduled, where $i=\{0,1$, $\ldots, n, n+1\} \in \mathrm{N}$, with 0 and $n+1$ being the two auxiliary (dummy) activities representing project start and finish, respectively

$d_{i} \quad$ normal duration assigned to each activity $i\left(d_{i} \geq 0\right)$ 
$c_{i} \quad$ crash duration assigned to each activity $i$ $\left(0 \leq c_{i} \leq d_{i}\right)$

$r_{i}^{\max }$ maximum time reduction in duration of activity $i$, where:

$$
r_{i}^{\max }=d_{i}-c_{i}
$$

$r_{i} \quad$ time reduction in duration of activity $i$ when crashing the project $\left(0 \leq r_{i} \leq r_{i}^{\max }\right)$

$s_{i} \quad$ start time of activity $i$ when crashing the project $\left(s_{i} \geq 0\right)$

$e_{i} \quad$ end time of activity $i$ when crashing the project, where:

$$
e_{i}=s_{i}+d_{i}-c_{i}
$$

$\mathrm{ES}_{i} \quad$ earliest start time of activity $i$

$\mathrm{EF}_{i} \quad$ earliest finish time of activity $i$

$\mathrm{LS}_{i} \quad$ latest start time of activity $i$

$\mathrm{LF}_{i} \quad$ latest finish time of activity $i$

$\mathrm{TF}_{i}$ total float (or slack) of activity $i$ where:

$$
\mathrm{TF}_{i}=\mathrm{LF}_{i}-\mathrm{EF}_{i}=\mathrm{LS}_{i}-\mathrm{ES}_{i}
$$

$\delta \quad$ time lag to each $\operatorname{arc}(a, b) \in \mathrm{R}$, where:

$$
\delta_{a b}+s_{a} \leq s_{b}
$$

being the temporal constraint with $s_{a}$ and $s_{b}$ the start times of activities $a$ and $b$; if $(a, b) \in \mathrm{R}$, activity $a$ cannot start earlier than $\delta_{a b}$ time units after the start of activity $a$; if $\delta_{a b}=d_{a}$, constraint (4) is referred to as the immediate precedence constraint between activities $a$ and $b$ assuming finish-to-start relationship without leads or lags $(\mathrm{FS}=0)$

$t^{n} \quad$ project completion time under normal conditions (according to traditional CPM calculations)

$t^{\max }$ project completion deadline (as specified by signed contractual agreement)

$t^{\text {min }}$ crash project completion time (minimum possible duration based on selected technology)

$t$ time units of construction production period (e.g., working months or weeks or days), where:

$t=\left\{0,1,2, \ldots, t^{\min }, \ldots, t^{n}, \ldots, t^{\max }\right\}$

$\mathrm{D}_{i}^{n} \quad$ direct cost for normal completion $\left(d_{i}\right)$ of activity $i$

$\mathrm{D}_{i}^{t} \quad$ direct cost per time unit for normal completion $\left(d_{i}\right)$ of activity $i$
$\mathrm{D}_{p}{ }^{n}$ total project direct cost for normal completion $\left(t^{n}\right)$, where:

$$
\mathrm{D}_{p}{ }^{n}=\sum\left(\mathrm{D}_{i}{ }^{n}\right)
$$

$\mathrm{D}_{i}^{c} \quad$ direct cost for crash completion $\left(c_{i}\right)$ of activity $i$

$\mathrm{D}_{p}{ }^{c}$ total project direct cost for crash completion $\left(t^{\mathrm{min}}\right)$, where:

$$
\mathrm{D}_{p}^{c}=\sum\left(\mathrm{D}_{i}^{c}\right)
$$

$\mathrm{A}_{i}$ additional direct cost for crash completion of activity $i$, where:

$$
\mathrm{A}_{i}=\left(\mathrm{D}_{i}{ }^{c}-\mathrm{D}_{i}{ }^{n}\right)
$$

$b_{i} \quad$ additional direct cost per time unit saved from crashing activity $i$ (crash cost slope), where:

$$
b_{i}=\left(\mathrm{D}_{i}^{c}-\mathrm{D}_{i}^{n}\right) /\left(c_{i}-d_{i}\right)=\left(\mathrm{A}_{i} / r_{i}^{\max }\right)
$$

$\mathrm{C}_{i}^{c} \quad$ crash cost for activity $i$, where:

$$
\mathrm{C}_{i}^{c}=b_{i} \cdot r_{i}
$$

$\mathrm{C}_{p}{ }^{c} \quad$ total project crash cost, where:

$$
\mathrm{C}_{p}{ }^{c}=\sum\left(\mathrm{C}_{i}{ }^{c}\right)=\sum\left(b_{i} \cdot r_{i}\right)
$$

$\mathrm{O}_{p}{ }^{t} \quad$ total project indirect expenses (overhead cost), where:

$$
\mathrm{O}_{p}{ }^{t}=\varepsilon \cdot t^{\min }
$$

with $\varepsilon$ being a fixed amount per time unit (normally calculated as a $\%$ of contract sum)

$\mathrm{C}_{p} \quad$ total project cost, where:

$$
\begin{aligned}
\mathrm{C}_{p}=\mathrm{D}_{p}{ }^{n}+\mathrm{C}_{p}{ }^{c}+ & +\mathrm{O}_{p}{ }^{t}=\sum_{\text {min }}\left(\mathrm{D}_{i}{ }^{c}\right)+\sum\left(b_{i} \cdot r_{i}\right) \\
& +\left(\varepsilon \cdot t^{\text {min }}\right)
\end{aligned}
$$

$\mathrm{S}_{p} \quad$ contract sum (contractor's winning bid), a fixed amount as signed in contractual arrangement

$\mathrm{P}_{p} \quad$ contractor's gross profit from project, where:

$$
\mathrm{P}_{p}=\mathrm{S}_{p}-\mathrm{C}_{p}
$$

According to equation (12), total project cost $\mathrm{C}_{p}$ is the sum of total direct cost $\mathrm{D}_{p}{ }^{n}$ for executing all project activities, plus total 
additional cost for crashing activities $\mathrm{C}_{p}{ }^{c}$ in order to achieve earlier project completion, plus total indirect (overhead) cost $\mathrm{O}_{p}{ }^{t}$ corresponding to the crash (minimum) project duration $t^{\mathrm{min}}$. Contractor's gross profit $\mathrm{P}_{p}$ from project's execution is derived from equation (13) as the difference between fixed contract sum $\mathrm{S}_{p}$ and total project cost $\mathrm{C}_{p}$. Therefore, minimising total project $\cos t \mathrm{C}_{p}$ results in maximising contractor's gross profit $\mathrm{P}_{p}$. The research aims at examining the relationship between minimum project duration $t^{\text {min }}$, overhead cost $\mathrm{O}_{p}{ }^{t}$ and gross profit $\mathrm{P}_{p}$. The latter is assumed to be greater than a minimum required level as set by the contracting organisation (as a percentage of contract sum):

$\mathrm{P}_{p}{ }^{\min }$ minimum contractor's gross profit anticipated from project, where:

$$
\mathrm{P}_{p}{ }^{\text {min }}=\varphi \cdot \mathrm{S}_{p}
$$

with $\varphi$ being a $\%$ of contract sum.

Thus, the linear programming (LP) mathematical model for solving the TCO problem is formulated as follows:

Objective function:

to minimize $z$, where:

$$
z=e_{n+1}
$$

(end time of dummy project finish activity)

Subject to constraints:

$$
r_{i} \leq r_{i}^{\max }
$$

(maximum reduction in activity duration)

$$
r_{i} \geq 0
$$

(non-negativity for reduction in activity duration)

$$
s_{i} \geq 0
$$

(non-negativity for activity start times)

$$
t \geq 0
$$

(non-negativity for project duration)

$$
t \leq t^{\max }
$$

(maximum project duration constraint)

$$
s_{i+1} \geq s_{i}+d_{i}-r_{i}
$$

(general start time precedence constraint)

$$
t \geq s_{n+1}+d_{n+1}-r_{n+1}
$$

$$
\mathrm{C}_{p} \leq \mathrm{S}_{p}
$$

(maximum total project cost constraint)

$$
\mathrm{P}_{p} \geq \mathrm{P}_{p}^{\text {min }}
$$

(minimum contractor's gross profit constraint)

The LP model (objective function 15 subject to constraints 16-24) can be easily implemented in a spreadsheet with a built-in optimisation tool (solver), e.g., Microsoft Excel ${ }^{\odot}$ with Solver addin, which is the software used in this research. Therefore, the LP can be solved several times for different levels of project indirect cost to calculate minimum project duration for a given percentage of contractor's profit. From the analysis, a trade-off curve for minimum project duration vs. level of overhead cost is derived, which can be used to assist management in project planning and control. A further useful analysis could be to investigate changes in the above relationship of crash duration and overheads by altering the level of anticipated profit from the project.

\section{MODEL IMPLEMENTATION: CONSTRUCTION OF A NEW PUBLIC NURSERY SCHOOL}

The proposed methodology is used to schedule the construction of an actual new three-storey reinforced concrete-framed public nursery building infrastructure project with a total gross floor area of approx. 910 sq.m. The building is expected to cover the educational needs of a municipality within the greater area of Northern Attica, Greece. The total contract sum $S_{p}$ for the project is $€ 1.200 .000$ (contractor's winning bid) and the associated contract duration (project deadline) $t^{\max }$, from the date of contractor's setup on site to the date of commissioning the project to the client, is 82 weeks.

The approved construction execution program (in the form of a Gantt chart) was carefully examined so that the PERT/CPM AoN project network was developed, assuming a finish-tostart immediate $(\mathrm{FS}=0)$ precedence relationship. The definition of work activities, the establishment of their technological precedence interrelationships, and their estimated normal (most likely) and crash (accelerated) times (durations $d_{i}$ and $c_{i}$ ) in weeks together with the corresponding estimated normal (most likely) and crash (increased) direct costs $\left(\mathrm{D}_{i}^{n}\right.$ and $\left.\mathrm{D}_{i}^{c}\right)$ in $€$ are shown in Table 1 . 
Table 1: Work activities with expected normal/crash duration and direct cost (author's own work)

\begin{tabular}{|c|c|c|c|c|c|c|}
\hline $\begin{array}{c}\text { Activity } \\
(i=0,1, \ldots, n, n+1)\end{array}$ & $\begin{array}{c}\text { Activity } \\
\text { no. }\end{array}$ & $\begin{array}{c}\text { Immediate } \\
\text { Predecessors }\end{array}$ & $\begin{array}{c}\text { Normal } \\
\text { Time } \\
\left(d_{i}\right)\end{array}$ & $\begin{array}{c}\text { Crash } \\
\text { Time } \\
\left(c_{i}\right)\end{array}$ & $\begin{array}{c}\text { Normal } \\
\text { Direct } \\
\text { Cost } \\
\left(D_{i}^{n}\right)\end{array}$ & $\begin{array}{c}\text { Crash } \\
\text { Direct } \\
\text { Cost } \\
\left(D_{i}^{c}\right)\end{array}$ \\
\hline Project Start (Dummy) & 0 & & 0 & 0 & 0 & 0 \\
\hline Site Setup/Demolitions & 1 & 0 & 3 & 2 & 8200 & 13120 \\
\hline Excavations & 2 & 1 & 4 & 3 & 18500 & 29600 \\
\hline RC Structural Frame & 3 & 2 & 14 & 10 & 145800 & 233280 \\
\hline Brickwork & 4 & 3 & 8 & 6 & 16100 & 25760 \\
\hline Metal Casing Pseudoframes & 5 & 4 & 2 & 1 & 2300 & 3680 \\
\hline Electrical 1st Fix (conduits) & 6 & 4 & 3 & 2 & 31900 & 51040 \\
\hline Plumbing (piping) & 7 & 4 & 4 & 3 & 42500 & 68000 \\
\hline Marble Sills & 8 & 4 & 2 & 1 & 2000 & 3200 \\
\hline Waterproofing/Roofs & 9 & 3 & 4 & 3 & 13700 & 21920 \\
\hline Plastering & 10 & $5 ; 6 ; 7 ; 8 ; 9$ & 9 & 6 & 16700 & 26720 \\
\hline Steelworks/Railings & 11 & 10 & 2 & 1 & 12000 & 19200 \\
\hline Electrical 2nd Fix (wiring) & 12 & 10 & 3 & 2 & 20100 & 32160 \\
\hline Walls Tiling & 13 & 11 & 2 & 1 & 4600 & 7360 \\
\hline Heating/Cooling/Gas/Solar (ducts) & 14 & 12 & 3 & 2 & 17200 & 27520 \\
\hline Floorings (marble, wooden, tiles) & 15 & $11 ; 13 ; 14$ & 6 & 4 & 13400 & 21440 \\
\hline Doors/Windows & 16 & 15 & 5 & 3 & 39200 & 62720 \\
\hline Joinery & 17 & 15 & 3 & 2 & 10400 & 16640 \\
\hline Bathrooms/WC Fixtures & 18 & 15 & 2 & 1 & 3500 & 5600 \\
\hline Boiler/Panels/Fan-coils Installation & 19 & 15 & 4 & 1 & 43200 & 69120 \\
\hline Elevator & 20 & $12 ; 14$ & 2 & 1 & 12000 & 19200 \\
\hline Plasterboard Ceilings & 21 & $19 ; 20$ & 2 & 1 & 7700 & 12320 \\
\hline Colourings & 22 & 21 & 10 & 7 & 18900 & 30240 \\
\hline Lighting/Electrical Finishing/Minor Works & 23 & $16 ; 17 ; 18$ & 3 & 2 & 17600 & 28160 \\
\hline Surrounding Area Works & 24 & $22 ; 23$ & 6 & 4 & 24700 & 39520 \\
\hline Operational Testing/Clean-up/Handover & 25 & 24 & 3 & 2 & 3300 & 5280 \\
\hline Project Finish (Dummy) & 26 & 25 & 0 & 0 & 0 & 0 \\
\hline
\end{tabular}

Using most likely durations and costs, the following PERT/CPM AoN network is constructed to identify the critical path and to estimate normal total figures for duration and direct cost over the whole project (Figure 3). The critical path is the longest path from start to finish and determines the overall project duration. Thus, the estimated total duration $t^{n}$ of the project is 79 weeks, three weeks earlier than contract deadline $t^{\max }$ (82 weeks). Total direct cost estimate $\mathrm{D}_{p}{ }^{n}$ is therefore $€ 545.500$ (the sum of normal direct cost $\mathrm{D}_{i}^{n}$ for each activity from Table 1). 


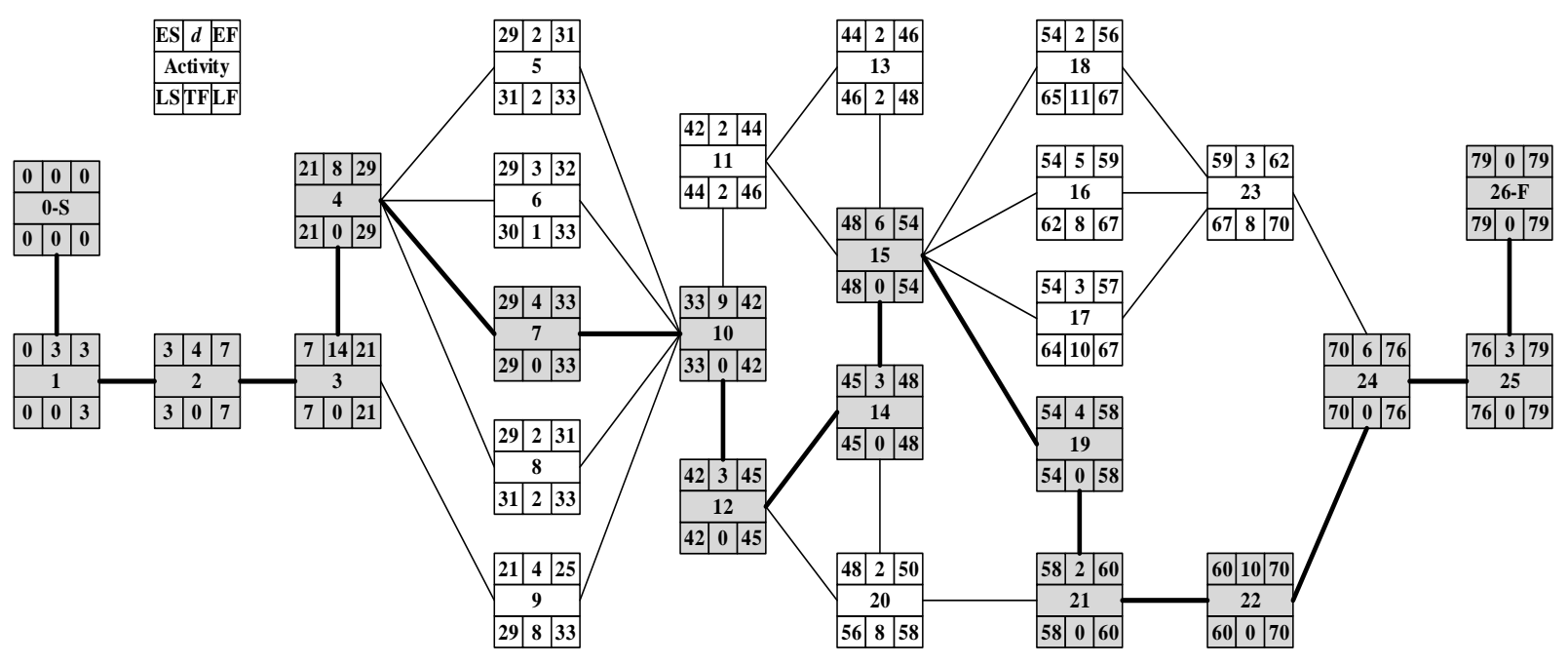

Figure 3: PERT/CPM AoN network graph assuming normal durations (author's own work)

Critical activities are represented by shaded boxes in Figure 3; the critical path is defined by their connecting (thicker) lines (S-1-2-3-4-7-1012-14-15-19-21-22-24-25-F). Critical activities are those with zero total float (TF) or slack. If work on this longest path is delayed, then, the entire project will be delayed. For this reason, the subset of critical activities must be kept on schedule to avoid time overruns.

The next step involves the repetitive solution of the LP, as previously developed in the third section of the paper, for a fixed percentage of expected profit $(\varphi=10 \%)$ and different amounts $\varepsilon$ of overheads per week, to obtain the resulting minimum (crash) project duration $t^{\text {min }}$ and the associated total cost for crashing critical activities $\mathrm{C}_{p}{ }^{c}$. For an anticipated gross profit level not less than $10 \%$, the minimum possible project duration ranges from 64 weeks to 53 weeks. The total additional crash cost $\mathrm{C}_{p}{ }^{c}$ for project compression is presented in Table 2 . Table 2 also includes: total indirect expenses $\mathrm{O}_{p}{ }^{t}$, total direct cost $\mathrm{D}_{p}{ }^{n}$ for normal completion, total gross profit $\mathrm{P}_{p}$, and total project $\operatorname{cost} \mathrm{C}_{p}$, for each project completion time. Total crash cost ranges from $€ 63.548$ for the duration of 64 weeks, to $€ 225.340$ for the duration of 53 weeks. Total overhead cost ranges from $€ 470.952$ (or else $39,2 \%$ of contract sum $S_{p}$ ) to $€ 309.160$ (or else $25,8 \%$ of contract sum $S_{p}$ ) for project duration from 64 weeks to 53 weeks, respectively. Table 3 shows which activities need to be compressed with their corresponding time reduction in weeks, for each possible crash project duration. All critical activities should be crashed to reduce project duration to 53 weeks.

Table 2: Synopsis of results from TCO model application for $\varphi=10 \%$ (author's own work)

\begin{tabular}{|c|c|c|c|c|c|c|c|c|c|c|c|}
\hline$t^{\min }$ & $\varepsilon$ & $\mathbf{O}_{p}{ }^{t}$ & $\% \mathbf{S}_{p}$ & $\mathrm{C}_{p}^{c}$ & $\% \mathbf{S}_{p}$ & $\mathrm{D}_{p}{ }^{n}$ & $\% \mathbf{S}_{p}$ & $\mathbf{P}_{p}$ & $\% \mathbf{S}_{p}$ & $\mathrm{C}_{p}$ & $\% \mathbf{S}_{p}$ \\
\hline 64 & 7330 & 470952 & $39,2 \%$ & 63548 & $5,3 \%$ & 545500 & $45,5 \%$ & 120000 & $10,0 \%$ & 1080000 & $90,0 \%$ \\
\hline 63 & 7310 & 460915 & $38,4 \%$ & 73585 & $6,1 \%$ & 545500 & $45,5 \%$ & 120000 & $10,0 \%$ & 1080000 & $90,0 \%$ \\
\hline 62 & 7290 & 452844 & $37,7 \%$ & 81656 & $6,8 \%$ & 545500 & $45,5 \%$ & 120000 & $10,0 \%$ & 1080000 & $90,0 \%$ \\
\hline 61 & 7270 & 445009 & $37,0 \%$ & 89491 & $7,5 \%$ & 545500 & $45,5 \%$ & 120000 & $10,0 \%$ & 1080000 & $90,0 \%$ \\
\hline 60 & 7230 & 435999 & $36,3 \%$ & 98501 & $8,2 \%$ & 545500 & $45,5 \%$ & 120000 & $10,0 \%$ & 1080000 & $90,0 \%$ \\
\hline 59 & 7180 & 427027 & $35,5 \%$ & 107473 & $9,0 \%$ & 545500 & $45,5 \%$ & 120000 & $10,0 \%$ & 1080000 & $90,0 \%$ \\
\hline 58 & 7100 & 414806 & $34,5 \%$ & 119694 & $10,0 \%$ & 545500 & $45,5 \%$ & 120000 & $10,0 \%$ & 1080000 & $90,0 \%$ \\
\hline 57 & 6930 & 398340 & $33,2 \%$ & 136160 & $11,3 \%$ & 545500 & $45,5 \%$ & 120000 & $10,0 \%$ & 1080000 & $90,0 \%$ \\
\hline 56 & 6670 & 376837 & $31,4 \%$ & 157663 & $13,1 \%$ & 545500 & $45,5 \%$ & 120000 & $10,0 \%$ & 1080000 & $90,0 \%$ \\
\hline 55 & 6390 & 354488 & $29,5 \%$ & 180012 & $15,0 \%$ & 545500 & $45,5 \%$ & 120000 & $10,0 \%$ & 1080000 & $90,0 \%$ \\
\hline 54 & 6110 & 332933 & $27,7 \%$ & 201567 & $16,8 \%$ & 545500 & $45,5 \%$ & 120000 & $10,0 \%$ & 1080000 & $90,0 \%$ \\
\hline 53 & 5780 & 309160 & $25,7 \%$ & 225340 & $18,8 \%$ & 545500 & $45,5 \%$ & 120000 & $10,0 \%$ & 1080000 & $90,0 \%$ \\
\hline
\end{tabular}


Table 3: Crashed activities with time reduction for each project duration (author's own work)

\begin{tabular}{|c|c|c|c|c|c|c|c|c|c|c|c|c|c|c|}
\hline$t^{\min }$ & \multicolumn{14}{|c|}{ Crashed Activities(Time Reduction in weeks) } \\
\hline 64 & $1(1)$ & $4(2)$ & $10(3)$ & $15(2)$ & $21(1)$ & $22(3)$ & $24(2)$ & $25(1)$ & - & - & - & - & - & - \\
\hline 63 & $1(1)$ & $4(2)$ & $10(3)$ & $15(2)$ & $19(1)$ & $21(1)$ & $22(3)$ & $24(2)$ & $25(1)$ & - & - & - & - & - \\
\hline 62 & 1(1) & $4(2)$ & $10(3)$ & $15(2)$ & $19(2)$ & $21(1)$ & $22(3)$ & $24(2)$ & $25(1)$ & - & - & - & - & - \\
\hline 61 & 1(1) & $4(2)$ & $10(3)$ & $15(2)$ & 19(3) & 21(1) & $22(3)$ & $24(2)$ & $25(1)$ & - & - & - & - & - \\
\hline 60 & $1(1)$ & $4(2)$ & $10(3)$ & $14(1)$ & $15(2)$ & $19(3)$ & $21(1)$ & $22(3)$ & $24(2)$ & $25(1)$ & - & - & - & - \\
\hline 59 & $1(1)$ & $2(1)$ & $4(2)$ & $10(3)$ & $14(1)$ & $15(2)$ & 19(3) & $21(1)$ & $22(3)$ & $24(2)$ & $25(1)$ & - & - & - \\
\hline 58 & $1(1)$ & $2(1)$ & $4(2)$ & $10(3)$ & $12(1)$ & $14(1)$ & $15(2)$ & 19(3) & 21(1) & $22(3)$ & $24(2)$ & $25(1)$ & - & - \\
\hline 57 & $1(1)$ & $2(1)$ & $3(1)$ & $4(2)$ & $10(3)$ & $12(1)$ & $14(1)$ & $15(2)$ & 19(3) & 21(1) & $22(3)$ & $24(2)$ & $25(1)$ & - \\
\hline 56 & $1(1)$ & $2(1)$ & $3(2)$ & $4(2)$ & $10(3)$ & $12(1)$ & $14(1)$ & $15(2)$ & 19(3) & $21(1)$ & $22(3)$ & $24(2)$ & $25(1)$ & - \\
\hline 55 & $1(1)$ & $2(1)$ & $3(3)$ & $4(2)$ & $10(3)$ & $12(1)$ & 14(1) & $15(2)$ & 19(3) & 21(1) & $22(3)$ & $24(2)$ & $25(1)$ & - \\
\hline 54 & $1(1)$ & $2(1)$ & $3(4)$ & $4(2)$ & $10(3)$ & $12(1)$ & $14(1)$ & $15(2)$ & 19(3) & 21(1) & $22(3)$ & $24(2)$ & $25(1)$ & - \\
\hline 53 & $1(1)$ & $2(1)$ & $3(4)$ & $4(2)$ & $7(1)$ & $10(3)$ & $12(1)$ & $14(1)$ & $15(2)$ & 19(3) & $21(1)$ & $22(3)$ & $24(2)$ & $25(1)$ \\
\hline
\end{tabular}

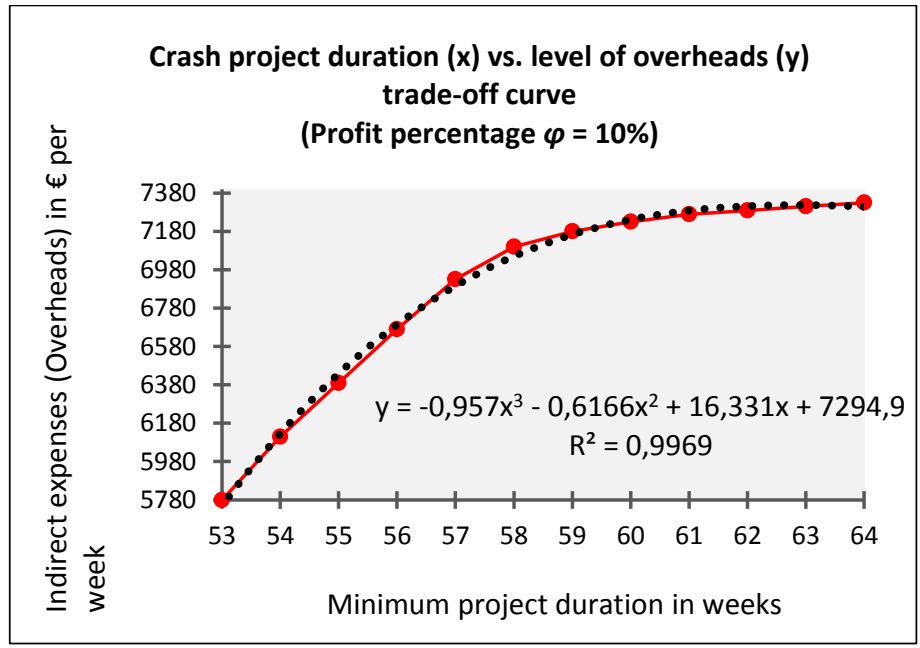

Figure 4: Trade-off curve for crash project duration vs. level of overheads (author's own work)

Figure 4 depicts the trade-off curve that overheads and crash project duration, for the describes the relationship between level of given contractor's profit percentage of $10 \%$.

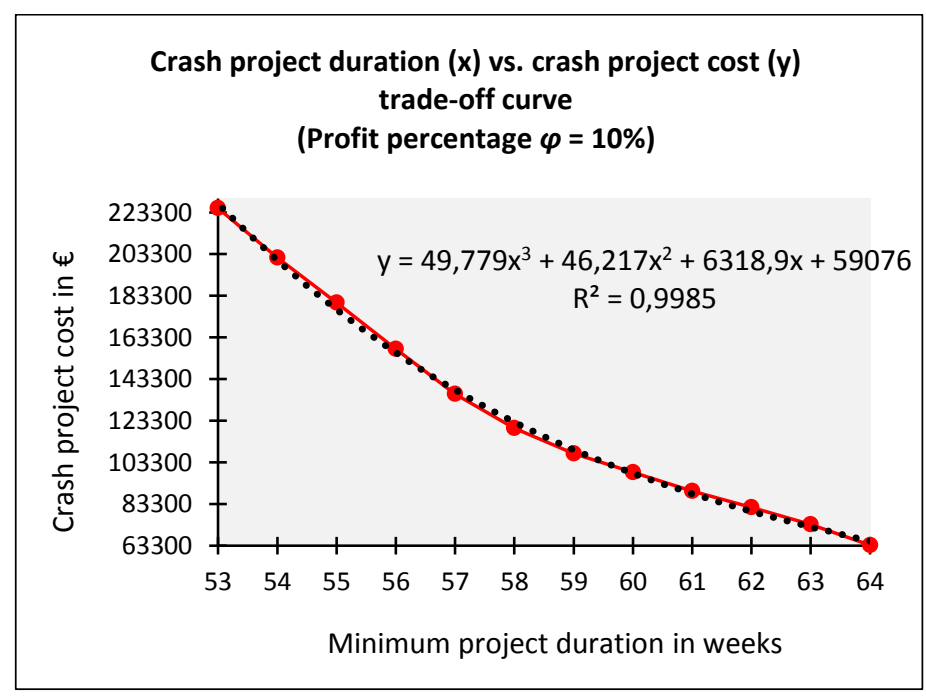

Figure 5: Trade-off curve for crash project duration vs. crash project cost (author's own work) 
Figure 5 shows the trade-off relationship between crash project duration and total crash cost, for the fixed $10 \%$ profit percentage. The above trade-off curves in Figures 4 and 5 can be of great value to project stakeholders when scheduling the building construction production phase by examining different possible time-cost optimisation scenarios.

Another useful analysis involves the investigation of changes in the above trade-off relationship between crash project duration and level of project overheads by altering the level of anticipated contractor's profit. If a rise in the profit margin from the project (say by $2,5 \%$ ) has been requested by contractor's board of directors, the LP model can be easily adjusted to calculate all relevant variables for the suggested new profit percentage $\varphi=12,5 \%$. The results from the TCO analysis are summarised in Table 4 and the new crash duration-level of overheads trade-off curve is illustrated in Figure 6. Finally, the effect on TCO of potential bonuses for early completion from the client to the contractor that can also be assessed by properly adjusting the herein proposed LP model, may be considered as an extension of this research work.

Table 4: Synopsis of results from TCO model application for $\varphi=12,5 \%$ (author's own work)

\begin{tabular}{|c|c|c|c|c|c|c|c|c|c|c|c|}
\hline$t^{\min }$ & $\varepsilon$ & $\mathbf{O}_{p}{ }^{t}$ & $\% \mathrm{~S}_{p}$ & $\mathrm{C}_{p}^{c}$ & $\% S_{p}$ & $\mathrm{D}_{p}{ }^{n}$ & $\% S_{p}$ & $\mathbf{P}_{p}$ & $\% S_{p}$ & $\mathbf{C}_{p}$ & $\% \mathrm{~S}_{p}$ \\
\hline 65 & 6870 & 47059 & $37,2 \%$ & 57441 & $4,8 \%$ & 545500 & $45,5 \%$ & 0 & $12,5 \%$ & 0 & $87,5 \%$ \\
\hline 64 & 6860 & 0 & & 6 & $5,5 \%$ & 545500 & $45,5 \%$ & 00 & & 050000 & $37,5 \%$ \\
\hline 63 & 6840 & 432 & 36 & 71 & $6,0 \%$ & 545500 & 45 & 00 & $\%$ & 00 & $87,5 \%$ \\
\hline 62 & 6810 & 423709 & $35,3 \%$ & 80791 & $6,7 \%$ & 545500 & $45,5 \%$ & 150000 & $5 \%$ & 1050000 & $87,5 \%$ \\
\hline 61 & 6780 & & 34 & & $7,4 \%$ & 545500 & $45,5 \%$ & 150000 & & 1050000 & $87,5 \%$ \\
\hline 60 & 6740 & 407299 & ,9\% & 97201 & $8,1 \%$ & 545500 & $45,5 \%$ & 150000 & $5 \%$ & 1050000 & $87,5 \%$ \\
\hline 59 & 6670 & 396 & $\%$ & 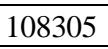 & $9,0 \%$ & 545500 & $45,5 \%$ & 150000 & $5 \%$ & 1050000 & $87,5 \%$ \\
\hline 58 & 6590 & 56 & $1 \%$ & 4 & $9,9 \%$ & 545500 & $45,5 \%$ & 150000 & $5 \%$ & 1050000 & $87,5 \%$ \\
\hline 57 & 6410 & & & & $1,3 \%$ & 545500 & $45,5 \%$ & 150000 & $5 \%$ & 1050000 & $87,5 \%$ \\
\hline 56 & 0 & 1 & $\%$ & 7 & $\%$ & 545500 & $5 \%$ & 0000 & $5 \%$ & 1050000 & $87,5 \%$ \\
\hline 55 & 5850 & & $27,0 \%$ & 179 & & 545500 & $45,5 \%$ & 150000 & $12,5 \%$ & 000 & $87,5 \%$ \\
\hline 54 & 5560 & 302974 & $25,2 \%$ & 201526 & $16,8 \%$ & 545500 & $45,5 \%$ & 150000 & $12,5 \%$ & 1050000 & $87,5 \%$ \\
\hline 53 & 5220 & 279219 & $23,2 \%$ & 225281 & $18,8 \%$ & 545500 & $45,5 \%$ & 150000 & $12,5 \%$ & 1050000 & $87,5 \%$ \\
\hline
\end{tabular}

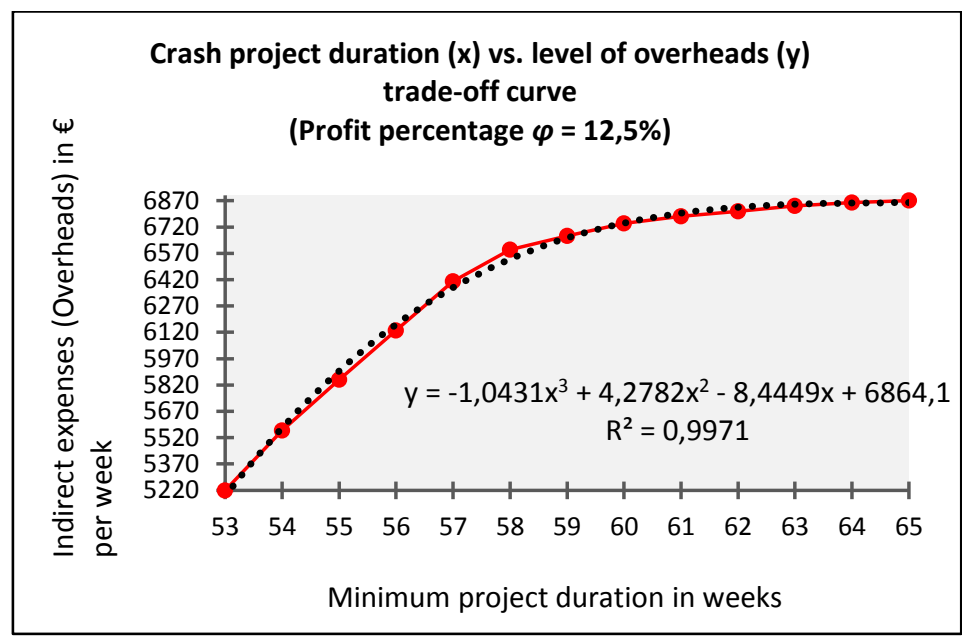

Figure 6: New trade-off curve for crash project duration vs. level of overheads (author's own work)

\section{CONCLUSION}

Effective planning of building infrastructure is crucial to their successful delivery by public works contractors to clients and to the society at 28 large. The optimal project duration for the construction production of a building infrastructure is a function of the technological order of the execution modes of its various activities, the human and mechanical resources 
required and the related direct and indirect expenses. Hence, effective scheduling of building projects is heavily dependent upon planning decisions on their time and cost targets. Project duration and expenses can only be "compressed" to certain time and cost figures and ideally to an optimum level; the solution to this so-called TCO problem is a demanding task faced by decision-makers in construction. However, despite the availability of numerous project management techniques and sophisticated software applications, the built environment is notorious for delivering products later than deadlines and over budget. One of the reasons, as suggested by current literature, is the ineffective management of general overheads. Therefore, it is advantageous for all project stakeholders to have a prior knowledge of overall time-cost profiles and understand the impact of potential changes in (fixed) indirect expenses on project success. The contribution of the herein presented LP spreadsheet model stems from its capability to facilitate sensitivity analysis, where the analyst can alter the inputs and conditions for the proposed project in a number of "what-if" analyses to facilitate project TCO decision-making. In addition, once the time-cost project baseline profile has been established and approved by the owner, a continuous comparison is possible of the actual performance with that planned, highlighting any deviations from the plan so that actions can be taken, either to bring things "back on track" or to modify the plan. The proposed approach may serve as a valuable tool for infrastructure scheduling by providing project stakeholders important insight into the relationship between level of overheads and total duration and cost of the project. From the analysis results, useful prototype trade-off curves are derived to support project management decisions.

The herein presented study is expected to assist both researchers and practitioners operating within the construction industry towards more effective decision-making in planning building projects. The optimisation of the construction project time-cost relationship can be of great significance to clients in highlighting the effect of "crashing" the work for early project completion on the maximisation of capital investment (notwithstanding the fact that total direct cost is increased). Nonetheless, it should be emphasized that the main difficulty with achieving an acceptable reliability level when applying TCO techniques lies in the accuracy and reliability of data related to additional (crash) costs for speeding-up the critical work activities. Hence, an immediate necessity arises for construction managers to collect accurate and relevant resource consumption data from historical projects if results are to be used as a sound basis for decision-making.

\section{REFERENCES}

Adeli, H., \& Karim, A. (1997). Scheduling/cost optimisation and neural dynamics model for construction, Journal of Construction Engineering and Management, 123(4), pp. 450-458.

Ahuja, V., \& Thiruvengadam, V. (2004). Project scheduling and monitoring: current research status, Construction Innovation, 4(1), pp. 19-31.

Albayrak, G., \& Özdemir, İ. (2017). A state of art review on metaheuristic methods in timecost trade-off problems, International Journal of Structural and Civil Engineering Research, 6(1), pp. 30-34.

Baldwin, A., \& Bordoli, D. (2014). A Handbook for Construction Planning and Scheduling, Wiley Blackwell, United Kingdom.

BCIS. (2012). Elemental Standard Form of Cost Analysis - Principles, Instructions, Elements and Definitions, $4^{\text {th }}$ (NRM) ed., RICS Building Cost Information Service (BCIS), London.

Brucker, P., Drexl, A., Möhring, R., Neumann, K., \& Pesch, E. (1999). Resourceconstrained project scheduling: notation, classification, models and methods, European Journal of Operational Research, 112(1), pp. 3-41.

Burns, S. A., Liu, L., \& Feng, C. W. (1996). The LP/IP hybrid method for construction timecost trade-off analysis", Construction Management and Economics, 14(3), pp. 265-276.

Chan, C. T. W., \& Pasquire, C. (2002). Estimation of project overheads: a contractor's perspective. In: Greenwood, D (Ed.), 18th Annual ARCOM Conference, 24 September 2002, University of Northumbria. Association of Researchers in Construction Management, 1, pp. 53-62. 
Chassiakos, A. P., \& Sakellaropoulos, S. P. (2005). Time-cost optimization of construction projects with generalized activity constraints, Journal of Construction Engineering and Management, 131(10), pp. 1115-1124.

CIOB. (2015). Code of Estimating Practice, $7^{\text {th }}$ ed., The Chartered Institute of Building (CIOB), Wiley Blackwell, United Kingdom.

Cusack, M. M. (1985). Optimisation of time and cost, International Journal of Project Management, 3(1), pp. 50-54.

De, P., Dunne, E. J., Ghosh, J. B., \& Wells, C. E. (1995). The discrete time-cost tradeoff problem revisited, European Journal of Operational Research, 81, pp. 225-238.

Deckro, R. F., Hebert, J. E., \& Verdini, W. A. (1995). Nonlinear time/cost tradeoff models in project management, Computers \& Industrial Engineering, 28(2), pp. 219-229.

Eksteen, B., \& Rosenberg, D. (2002). The management of overhead costs in construction companies. In: Greenwood, D. (Ed.), 18th Annual ARCOM Conference, 24 September 2002, University of Northumbria. Association of Researchers in Construction Management, 1, pp. 13-22.

Elazouni, A., Alghazi, A., \& Selim, S. Z. (2015). Finance-based scheduling using metaheuristics: discrete versus continuous optimization problems, Journal of Financial Management of Property and Construction, 20(1), pp. 85-104.

Elbeltagi, E., Hegazy, T., \& Grierson, D. (2005). Comparison among five evolutionary-based optimisation algorithms, Advanced Engineering Informatics, 19(1), pp. 43-53.

El-Kholy, A. M. (2013). Time-cost tradeoff analysis considering funding variability and time uncertainty, Alexandria Engineering Journal, 52(1), pp. 113-121.

El-Rayes, K., \& Kandil, A. (2005). Time-costquality trade-off analysis for highway construction, Journal of Construction Engineering and Management, 131(4), pp. 477-486.

Enshassi, A., Rashid Abdul Aziz, A., \& El Karriri, A. (2008). Investigating the overhead costs in construction projects in Palestine", Journal of Financial Management of Property and Construction, 13(1), pp. 35-47.
Eshtehardian, E., Afshar, A., \& Abbasnia, R. (2009). Fuzzy-based MOGA approach to stochastic time-cost trade-off problem, Automation in Construction, 18(5), pp. 692701.

Falk, J. E., \& Horowitz, J. L. (1972). Critical Path Problems with Concave Cost-Time Curves, Management Science, 19(4), pp. 446-455.

Feng, C. W., Liu, L., \& Burns, S. A. (1997). Using genetic algorithms to solve construction time-cost trade-off problems, Journal of Computing in Civil Engineering, 11(3), pp. 184-189.

Feng, C. W., Liu, L., \& Burns, S. A. (2000) "Stochastic construction time-cost trade-off analysis", Journal of Computing in Civil Engineering, 14(2), pp. 117-126.

Foldes, S., \& Sourmis, F. (1993). PERT and crashing revisited: Mathematical generalizations, European Journal of Operational Research, 64, pp. 286-294.

Fondahl, J. W. (1961). A non-computer approach to the critical path method for the construction industry, Technical Report No. 9, Department of Civil Engineering, Stanford University, CA.

Fulkerson, R. D. (1961). A network flow computation for project cost curves, Management Science, 7(2), pp. 167-168.

Goyal, S. K. (1975). A Note on A Simple CPM Time-Cost Algorithm, Management Science, 21(6), pp. 718-722.

Hajdu, M. (2013). Network Scheduling Techniques for Construction Project Management, Springer-Science + Business Media B.V.

Hegazy, T. (1999). Optimisation of Resource Allocation and Levelling Using Genetic Algorithms, Journal of Construction Engineering and Management, 125(3), May-June.

Kalhor, E., Khanzadi, M., Eshtehardian, E., \& Afshar, A. (2011). Stochastic time-cost optimisation using non-dominated archiving ant colony approach, Automation in Construction, 20(8), pp. 1193-1203.

Kelley, J. E. (1961). Critical-path planning and scheduling: Mathematical basis, Operations Research, 9(3), pp. 167-179.

Kelley, J. E., \& Walker, M. R. (1959). CriticalPath Planning and Scheduling, Proceedings of the Eastern Joint Computer Conference, New York, USA, December, pp. 160-173. 
Li, H., \& Love, P. (1997). Using improved genetic algorithms to facilitate time-cost optimization, Journal of Construction Engineering and Management, 123(3), pp. 233-237.

Liu, L., Burns, S. A., \& Feng, C. W. (1995). Construction time-cost trade-off analysis using LP/IP hybrid method, Journal of Construction Engineering and Management, 121(4), pp. 446-454.

Lockyer, K. G. (1974). An Introduction to Critical Path Analysis, $3^{\text {rd }}$ ed., Pitman, London.

Maghrebi, M., Afshar, A., \& Maghrebi, M. J. (2013). A Novel Mathematical Model for Deterministic Time-Cost Trade-off Based on Path Constraint, International Journal of Construction Engineering and Management, 2(5), pp. 137-142.

Meyer, W. L., \& Shaffer, L. R. (1963). Extensions of the critical path through the application of integer programming, Report issued by the Department of Civil Engineering, University of Illinois.

Moselhi, O. (1993). Schedule compression using the direct stiffness method, Canadian Journal of Civil Engineering, 20, pp. 65-72.

Moselhi, O., \& Roofigari-Esfahan, N. (2013). Project schedule compression: a multiobjective methodology, Construction Innovation, 13(4), pp. 374-393.

Moussourakis, J., \& Haksever, C. (2004). Flexible model for time/cost trade-off problem, Journal of Construction Engineering and Management, 130(3), pp. 307-314.

Mubarak, S. (2015). Construction Project Scheduling and Control, $3^{\text {rd }}$ ed., John Wiley \& Sons, New Jersey.

Ng, S. T., \& Zhang, Y. (2008). Optimizing construction time and cost using ant colony optimization approach, Journal of Construction Engineering and Management, 134(9), pp. 721-728.

Oxley, R., \& Poskitt, J. (1996). Management Techniques Applied to the Construction Industry, $5^{\text {th }}$ ed., Blackwell Science, Oxford.

Prager, W. (1963). A structured method of computing project cost-polygons, Management Science, 9(3), pp. 394-404.
Raz, T., \& Elnathan, D. (1999). Activity based costing for projects, International Journal of Project Management, 17(1), pp. 61-67.

Reda, R. M., \& Carr, R. I. (1989). Time-cost trade-off among related activities, Journal of Construction Engineering and Management, 115(3), pp. 475-486.

Robinson, D. R. (1975). A dynamic programming solution to cost-time trade-off for CPM, Management Science, 22(2), pp. 158-166.

Sears, S. K., Sears, G. A., Clough, R. H., Rounds, J. L., \& Segner, R. O. (2015). Construction Project Management: A Practical Guide to Field Construction, $6^{\text {th }}$ ed., Wiley, United States.

Siemens, N. (1971). A Simple CPM Time-Cost Trade-off Algorithm, Management Science, 17(6), pp. 354-363.

Skutella, M. (1998). Approximation Algorithms for the Discrete Time-Cost Trade-off Problem, Mathematics of Operations Research, 23(4), pp. 909-929.

Sonmez, R., \& Bettemir, Ö. H. (2012). A hybrid genetic algorithm for the discrete time-cost trade-off problem, Expert Systems with Applications, 39(13), pp. 11428-11434.

Vanhoucke, M. (2013). Project Management with Dynamic Scheduling: Baseline Scheduling, Risk Analysis and Project Control, $2^{\text {nd }}$ ed., Springer.

Vanhoucke, M., \& Debels, D. (2007). The discrete time/cost trade-off problem under various assumptions exact and heuristic procedures, Journal of Scheduling, 10, pp. 301-326.

Westney, R. E. (ed.) (1997). The Engineer's Cost Handbook: Tools for Managing Project Costs, Marcel Decker Inc., New York.

Williams, T. (2003). The contribution of mathematical modelling to the practice of project management, IMA Journal of Management Mathematics, 14(1), pp. 3-30.

Yang, I.-T. (2005). Impact of Budget Uncertainty on Project Time-Cost Trade-off, IEEE Transactions of Engineering Management, 52(2), pp. 167-174.

Yang, X., Yuan, J., \& Mao, H. (2007). A modified particle swarm optimizer with dynamic adaptation, Applied Mathematics and Computation, 189, pp. 1205-1213. 